\title{
Social-Economic Approach to an eParticipation experience based on eCognocracy
}

\author{
Cristina Pérez-Espés ${ }^{1}$, José María Moreno-Jiménez ${ }^{1}$ \\ ${ }^{1}$ University of Zaragoza, Gran Via 2, \\ 50005 Zaragoza, Spain \\ perezesp@unizar.es, moreno@unizar.es
}

\begin{abstract}
Most eParticipation initiatives have social, economic and environmental costs, financed in most cases with public funds, so it would be convenient to evaluate them in order to be transparent and consistent with the strategic objectives pursued. Thus, it is necessary to quantify, monetarily, both the economic, social and environmental aspects, and the value added generated by the practical application of this type of eParticipation initiatives. The main objective of this paper is to value, in monetary terms, the social and economic aspects of the implementation and development of an eParticipation experience based on eCognocracy. This evaluation will allow us to obtain the social and economic information as to the true value added that these initiatives contribute to society in general, and to give an appropriate answer to the new challenges and necessities in the sphere of public decisions that arise within the Knowledge Society.
\end{abstract}

Keywords: eParticipation, eCognocracy, Social Return On Investment (SROI), social-economic approach

\section{Introduction}

The concept of eGovernment appeared, its evolution has led to the search for multiple attempts at modernization and innovation in the field of public management [1], [2]. The activities of the public sector in the following years have focused, among other things, on citizen involvement in the political process through eParticipation.

The presence of the citizenry in institutional environments in which the management and design of public policies are defined and specified introduces a capacity of control that helps to reduce one of the fundamental imbalances in the relations between the State and civil society. In effect, citizen participation not only enables citizens to propose initiatives, carry out consultations, improve their level of information, and participate in certain decision processes but also to control and monitor institutional activity.

Building this context it should be enabled experiences of eParticipation that exploit the potential of the knowledge society and respond to its new challenges and needs. In this way, eCognocracy [3], [4] is a new cognitive democracy that combining 
the representative and the direct democracy pursues the creation and social diffusion of knowledge relative to the scientific resolution of public decision making problems.

All these participative experiences and processes, in which the citizen is directly involved, have a clear impact on material, social and economic questions. The analysis of the economic and social component of an eParticipation experience is considered fundamental and necessary in order to be able to study its final impact on society.

Taking into account the great efforts of public administrations to maintain a high degree of transparency in the implementation of eGovernment services projects, they justify their budgets through studies that describe comparative analyses of cost information between the traditional way of serving citizens and the IT-based solutions. Nevertheless, due to the lack of established methodologies for calculating the costs and assessing the benefits of implementing eGovernment services, these studies often contain analyses that do not reflect the reality of the costs [5].

Moreover, in accordance with new social requirements and with the properties of transparency and accountability recommended for any process financed through public funds, as habitually occurs in eParticipation experiences, the public powers have to take decisions as to where to invest resources. An economic-social analysis is a useful tool to evaluate and study the value created by the implantation of projects and initiatives and can serve as a guide in public decisions to channel resources towards the experiences that provide greater net benefit to society.

In this paper, we carry out an analysis, in monetary terms, of the economic and social aspects of the implementation and development of an eParticipation experience based on eCognocracy (the Cadrete case), using an advanced management tool called Social Return on Investment (SROI). This analysis, allows us, through the comparison of the economic and social benefits with the investment made, to obtain a global vision of the true value added that eParticipation initiatives provide for society.

This article is structured as follows: after this brief introduction, Section 2 covers the economic-social valuation of the eParticipation experiences; Section 3 presents the tool SROI and its application in our case of study. And section 4 shows the main conclusions that can be drawn from the work and the future research lines.

\section{Economic-Social valuation of the eParticipation experiences}

This section presents a review of the literature on the economic and social valuation of projects and initiatives carried out by the government and the possible methodologies that can be applied to evaluate an eParticipation experience in monetary terms.

\subsection{Background}

The work of Matusuda and others [6] evaluates, through AHP, the importance of carrying out social programs that contribute to the social welfare of elderly people belonging to the community of Fukuoka (Japan).

Bhatnagar [7], as well as identifying the goals and objectives to be achieved in different initiatives of electronic government, establishes how to attain the objectives fixed so that they have an impact. To do so, the author focuses on a compilation of various examples of eGovernment applications in different countries including Korea, Mexico, India and the Philippines. 
Gupta and Jana [8] study the evaluation of eGovernment through a framework that suggests choosing a strategy to measure the tangible and intangible benefits of the application of eGovernment initiatives in society.

Hadzilas [5] proposes a structured framework for calculating the cost of eGovernment services, based on the complementary application of the IDEF0 modelling tool and the Activity-Based Costing technique.

Other papers, such as Ajilian and Crameri [9] analyze the possible economic and social impact of an effective and efficient electronic administration on society. They show that the use of ICT not only improves the interactions between the administration, citizens, businesses and industries but also has positively affected the quality and delivery of services.

Jens Loff [10] studies, using cost-benefit analysis (CBA), whether it is profitable, both in economic and social terms, to implement a participation project. This work was presented for the European Public Sector Award (EPSA). Another example that uses CBA as its evaluation tool is that of Fernando Cuenin [11]. The main aim of this study was to give a general idea about how the economic analysis of projects could aid the design, monitoring and evaluation of operations, focusing on the particular case of neighborhood improvement programs.

\subsection{Methodologies}

This section describes different tools that allow the evaluation of a project or an initiative in monetary terms.

The numerous references in the literature lead us to the conclusion that CostBenefit Analysis (CBA), Multi-criteria Decision-Making (MCDM) Techniques, Icam DEFinition for Function Modeling (IDEFo), Activity-based costing (ABC) and Social Return on Investment (SROI) are among the most widely-used tools in decision making, especially in the public sector.

Cost-Benefit Analysis is one of the methods most used in the sphere of Public Administration to analyze its own behavior. CBA is, basically, the rationalization of a daily practice: weighing up the advantages and disadvantages of any decision or alternative, whether by itself or in comparison with others [12]. CBA is a tool that permits the evaluation of the costs and benefits of a project (program, intervention or political measure) with the aim of determining whether the project is desirable from the social welfare point of view and, if it is, to what extent.

On occasions, the analyst is faced with a double-edged problem that impedes the use of CBA [12]: i) some of the costs and benefits identified cannot be reduced to the number previously established and ii) the decision maker, or some of the social groups that take part in the process of collective decision, consider that this reduction should not be carried out, that is, they reject the use, for example, of the economic value of statistics.

In both cases, the analyst is deprived of the possibility of reducing all the costs and benefits to a single figure that permits direct comparison. To resolve this type of problem, one of the tools proposed are the Multi-criteria Decision-Making (MCDM) Techniques. The origin of these techniques is the same as the conventional BCA: the necessity of maximizing a function that depends on a series of well-specified objectives but with the difference that, now, they can present conflicts among themselves. The methods of multi-criteria evaluation and decision-making consist of selecting, 
from among a set of feasible alternatives, the optimization with various simultaneous objective functions and just one decision maker, and procedures of rational and consistent evaluation [13].

IDEF0, a compound acronym (Icam DEFinition for Function Modeling, where 'ICAM' is an acronym for Integrated Computer Aided Manufacturing), is a function modeling methodology for describing manufacturing functions which offers a functional modeling language for the analysis, development, reengineering, and integration of information systems, business processes, or software engineering analysis ${ }^{1}$. IDEFo was developed by the US Air Force under its ICAM program. The key principle of IDEFo is that complex systems can be explained in terms of the activities performed in the system and in such a way as to present details progressively through a hierarchical decomposition [14].

Another evaluation method is that of Activity Based Costing (ABC). This method was first clearly defined in 1987 by Kaplan, Robert S. and W. Bruns as a chapter in their book Accounting and Management: A Field Study Perspective [15]. According to CIMA (Chartered Institute of Management Accountants), ABC can be defined as an approach to the costing and monitoring of activities which involves tracing resource consumption and costing final outputs. Resources are assigned to activities, and activities to cost objects based on consumption estimates. The latter utilize cost drivers to attach activity costs to outputs.

Lastly, it is necessary to refer to one of the methods most employed to measure the social, environmental and economic impacts in public decision making, the Social Return on Investment (SROI), which is dealt with in detail in the next section.

\section{Social Return On Investment}

Social Return on Investment is a methodology created in the mid-1990s in San Francisco and intended to evaluate investments in social organizations. It was later revised in 2000 by New Economics Foundation with the collaboration of public administrations in the United Kingdom.

SROI is a participative approach that permits the monetary calculation of the value of a wide range of results, whether they have a market value or not. It is a tool with which both the managers of and the investors in a project can take decisions based on the optimization of the social and environmental impacts of the project.

It is a method that adds principles of measurement of extra-financial value with respect to the resources invested, that is, the social and environmental value that, at present, is not reflected in conventional financial accounts. SROI also incorporates the concept of return, which, in financial terms, simply refers to the benefits received as a result of an investment.

The use of this tool illustrates how an organization, program, project, initiative, etc., creates value and a coefficient that indicates how much total value in euros is created for each euro invested.

This SROI coefficient is a comparison between the value generated by an initiative and the investment necessary to achieve this impact. SROI seeks more than to

\footnotetext{
${ }^{1}$ Systems Engineering Fundamentals. Defense Acquisition University Press, 2001.
} 
obtain a simple number because the method describes the process for reaching the final ratio and contextualizes the information to permit its correct interpretation. Furthermore, it presents a framework to explore the social and environmental impacts of an organization in which monetization plays an important, but not exclusive, role.

There are two types of SROI analysis: i) evaluation, that is carried out a posteriori and on the basis of the real results already obtained (measurement of the impact of finished projects) and ii) forecasting, that predicts the social value that will be created if the activities achieve the foreseen results (especially useful in the planning stages of an initiative). The two types of SROI can be combined to include both the results already attained and future ones [16].

The SROI methodology has been widely used for the calculation of the impact of the triple dimension -social, environmental and economic-, containing all externalities, whether they have market value or not. SROI, as has been commented previously, is a participative approach that permits the capture, in monetary terms, of the value of a wide range of results, whether they have economic value or not. The effects derived from the implementation and development of an e-Participation experience are not only economic but, in most cases, social and environmental. The need to quantify, in monetary terms, the contribution of the whole participation process, as well as the value created, leads us to carry out a SROI analysis that will be useful in the sense that it generates relevant information for decision making. Moreover, SROI helps us to understand, manage and communicate the social value that our work creates in a clear and consistent way for customers, beneficiaries and funders. It will bring out potential improvements to services and information systems. A consistent approach to understanding and accounting for social value means that you can communicate clearly where and how you create value in a credible way ${ }^{2}$. All the above has let us to apply this methodology in our case study.

\subsection{SROI analysis for the Cadrete experience}

This section presents each of the steps carried out to calculate the SROI coefficient of the Cadrete initiative based on eCognocracy.

\subsubsection{Description of the experience}

In April 2010, the Cadrete Municipal Council, in collaboration with Zaragoza Multicriteria Decision Making Group (GDMZ), implemented a citizen participation project (https://participa.cadrete.es) aimed at giving the residents of the municipality a voice in public policy decisions. The issue in question was the design of cultural and sporting policies. There was one objective for the GDMZ: the validation of the methodological and technological tools and two main objectives for the City Council: (i) that decisions on the budget assigned to the aforementioned policies would be conjointly made by the politicians and the citizenry; (ii) that citizens would be encouraged to involve themselves in the debate and take part in the decision making process, and more specifically, that the arguments that supported the decisions would be publicly disseminated.

This eParticipation experience consisted of the following phases, which correspond to the basic structure of the model of democracy known as eCognocracy [17]:

\footnotetext{
${ }^{2}$ http://www.thesroinetwork.org/117-home/all-regions/167-why-should-i-use-sroi10
} 
i) problem formulation, ii) information and training, iii) modeling the problem, iv) first round of voting, v) discussion, vi) second round of voting and vii) presentation of the results.

\subsubsection{Determining the scope}

1. Proposal

The objective of this analysis is to measure the impact that the Cadrete experience has had on society, as well as the value created by the practical application of this initiative.

This is an evaluation analysis because it is carried out a posteriori and is based on the real results obtained 4 years after putting the experience into practice.

2. Public/Receivers

The receivers of our SROI analysis are all those to whom we must be held accountable (being, above all, transparent) for the project financed mainly by public funds: i) Citizens and society in general; ii) Financing entities: Council of Cadrete, Government of Aragón and the Uni versity of Zaragoza; iii) Promoter of the initiative: the Zaragoza Multi-criteria Decision Making Group.

This analysis is also addressed to the "science of research" to serve as a guide and to be improved in other experiences.

\section{Context}

There are more and more eParticipation experiences carried out in society in which, among other things, citizen participation in public decision making is fomented. As a consequence, a need arises to measure the economic, social and environmental impact of these initiatives as well as the value added they generate.

4. Resources

To carry out the SROI analysis, we had, as personnel resources, all the members of the Zaragoza Multi-criteria Decision Making Group. The expenditure arising from the carrying out of this report was financed by the GDMZ.

5. Analysis team

The personnel that carried out the SROI analysis are the members of the Zaragoza Multi-criteria Decision Making Group, who were the promoters of the initiative.

6. The range of activities to be included

The topic of the Cadrete experience was the design of cultural and sporting policies. There were two main objectives for the research group: the implementation of the experience and the validation of the methodological and technological tools; and the three objectives for the City Council: (i) that decisions on the budget assigned to the aforementioned policies would be conjointly made by the politicians and the citizenry; (ii) that citizens would be encouraged to involve themselves in the debate and take part in the decision making process; and iii) that the arguments that supported the decisions would be publicly disseminated.

The activities to be included in the SROI analysis are all those that were necessary for implementing the experience. Therefore, most of them coincide with 
the stages, grouped into 4 blocks, of the methodology followed by eCognocracy [17].

7. Time range to analyze

The Cadrete experience was carried out in 2010. This report was drawn up in 2014 , but the period to be analyzed is of 1 year (from 2010-short term).

\subsubsection{Identification and incorporation of the actors involved}

The actors or groups of interest (stakeholders) that we have taken into account for carrying out the SROI analysis are all those directly affected by the experience: the municipal council, the citizens of Cadrete and its surroundings and the promoter of the experience, the GDMZ.

\subsubsection{Identification Inputs}

Table 1 shows, in detail, all the inputs used to carry out the Cadrete experience.

Table 1. Inputs of the Cadrete experience

\begin{tabular}{|c|c|}
\hline \multirow{2}{*}{\multicolumn{2}{|c|}{ 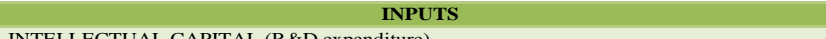 }} \\
\hline & \\
\hline \multicolumn{2}{|c|}{$\begin{array}{l}\text { INTELLECTUAL CAPITAL (R\&D expenditure) } \\
- \\
\text { Use of intellectual capital: } N^{\circ} \text { of researchers participating ( } 4 \text { people in the Counci } \\
\text { and } 15 \text { from GDMZ), meetings and weekly debates during } 1 \text { year }(35) \text {. }\end{array}$} \\
\hline \multicolumn{2}{|c|}{ MATERIAL RESOURCES } \\
\hline \multicolumn{2}{|r|}{ - Installations: 4 rooms } \\
\hline \\
\hline & $\begin{array}{l}\text { Computer equipment (hardware): } 12 \text { computers } \\
\text { Software: Voting Applet in Java } 6.18\end{array}$ \\
\hline \multicolumn{2}{|r|}{ Technological tools: 1 projector } \\
\hline & $\begin{array}{l}\text { Technological tools: } 1 \text { projector } \\
\text { Web browsers: Mozilla and Internet Explorer } 8\end{array}$ \\
\hline \multicolumn{2}{|r|}{ Documentation: } \\
\hline \multicolumn{2}{|r|}{$\begin{array}{l}\text { Documentation: } \\
-\quad 1600 \text { leaflets }\end{array}$} \\
\hline \multicolumn{2}{|r|}{ - 1949 letters sent to citizens } \\
\hline \multicolumn{2}{|r|}{ - 15 letters sent to associations } \\
\hline \multicolumn{2}{|r|}{ - 20 posters } \\
\hline \multicolumn{2}{|r|}{ - 1 online guide } \\
\hline & - 1 questionnaire \\
\hline & - 1 final report \\
\hline \multirow{2}{*}{\multicolumn{2}{|c|}{$\begin{array}{l}\text { Web pages: } 1 \text { web page for the experience } \\
\text { Other materials: }\end{array}$}} \\
\hline & \\
\hline \multicolumn{2}{|r|}{$\begin{array}{l}\text { Other materials: } \\
\quad-\quad 1 \text { bracelet for fairground }\end{array}$} \\
\hline \multicolumn{2}{|r|}{ - 1 cultural excursion } \\
\hline \multicolumn{2}{|r|}{ - 2 quarterly gym season tickets } \\
\hline \multicolumn{2}{|r|}{ - $\quad 3$ inscriptions in sporting activities } \\
\hline \multicolumn{2}{|r|}{ - $\quad 4$ swimming pool season tickets } \\
\hline \multicolumn{2}{|r|}{ - 20 USB memories } \\
\hline \multicolumn{2}{|r|}{ - 30 electronic ID readers } \\
\hline \multicolumn{2}{|c|}{ HUMAN RESOURCES } \\
\hline \multirow{2}{*}{\multicolumn{2}{|c|}{$\begin{array}{ll}\text { - } & \text { Council personnel: } 4 \text { people: Mayoress, Secretary and } 2 \text { technicians } \\
\text { - } & \text { Personal del GDMZ: } 15 \text { people }\end{array}$}} \\
\hline & \\
\hline \\
\hline & - $\quad$ Mathematical modeling (3 people): Associate Professor (AP), 1 Graduate \\
\hline & (G) and 1 Fellow (F). \\
\hline & $\begin{array}{l}\text { Intelligent Data Analysis (3 people): } 1 \text { Associate Professor (AP) and } 2 \\
\text { Assistant Lecturers (AL) }\end{array}$ \\
\hline & - $\quad \frac{\text { Informatics developments (3 people): } 2 \text { Associate Professors (AP) and } 1}{\text { technician (G) }}$ \\
\hline & - Communications Technology Group (1 person/Engineer): Graduate (G) \\
\hline & - 4 Political Scientists: Graduates (G) \\
\hline - & Collaborators (1 person): Associate Professor (AP) \\
\hline & - Evaluation of the experience: 1 person (AP) (design of the questionnaire) \\
\hline TIME $\mathrm{F}$ & ICTOR \\
\hline Time is & Iso a resource used in this experience. \\
\hline OTHEF & EXPENDITURE \\
\hline- & $\begin{array}{l}\text { Other allowances: Meal tickets (14) } \\
\text { Travel allowances (Zaragoza-Cadrete-Zaragoza_24km): } 12\end{array}$ \\
\hline
\end{tabular}


Research and development (R\&D) expenditures are understood to be "current and capital expenditures (both public and private) on creative work undertaken systematically to increase knowledge, including knowledge of humanity, culture, and society, and the use of knowledge for new applications. R\&D covers basic research, applied research, and experimental development." (World Bank ${ }^{3}$ ). We have accounted for this type of expenditure through the number of researchers who participated in this experience as well as the number of meetings and the time employed in each of them.

Material resources are the goods and/or physical and tangible means necessary to achieve an objective, for example, installations, computer equipment (hardware), software, documentation etc.

Human resources include all the people who contribute work to an organization (whether profit-motivated or not and from any type of association).

The time factor encompasses the time invested in the implementation and development of the initiative.

The item "other expenditure" includes all the other expenditure incurred by an organization in achieving its objectives. In the case of the Cadrete experience, it includes allowances and travel expenses between Zaragoza and Cadrete.

All the inputs used and expenditures incurred in the experience were quantified, in monetary terms, for each of the stages that form part of the methodology followed by eCognocracy. In this way, we individually accounted for the implementation cost of each stage of the Cadrete experience. The total cost was $42046.73 €$.

\subsubsection{Identification Outcomes}

This section presents the quantification, in monetary units, of the results through the use of financial proxies for each of the stakeholders (see Table 2, 3 and 4). The total outcomes were $115623.50 €$.

Table 2. Proxies for the indicators of outcomes (council)

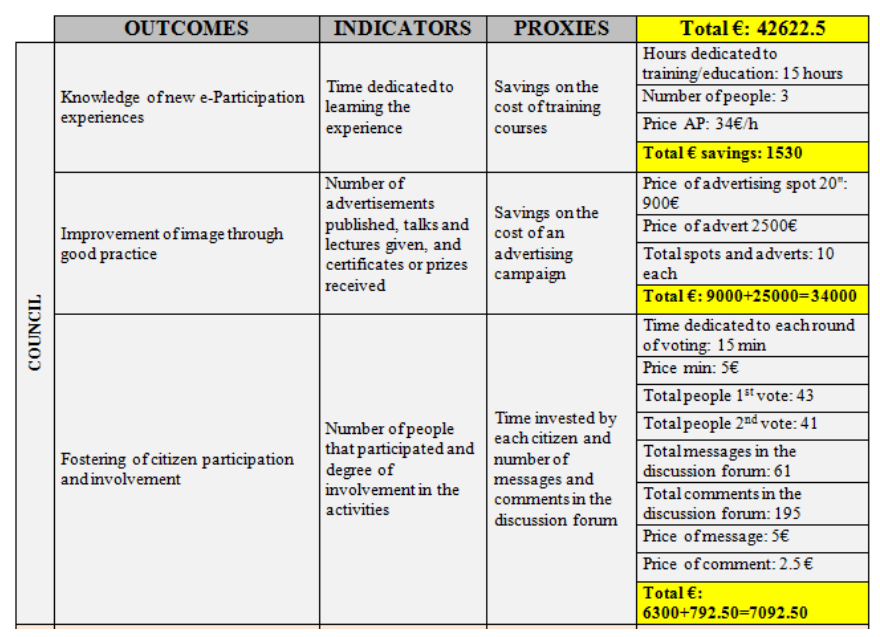

\footnotetext{
${ }^{3}$ http://datos.bancomundial.org/indicador/GB.XPD.RSDV.GD.ZS/countries/1W?display=graph
} 
Table 3. Proxies for the indicators of outcomes (citizens of Cadrete)

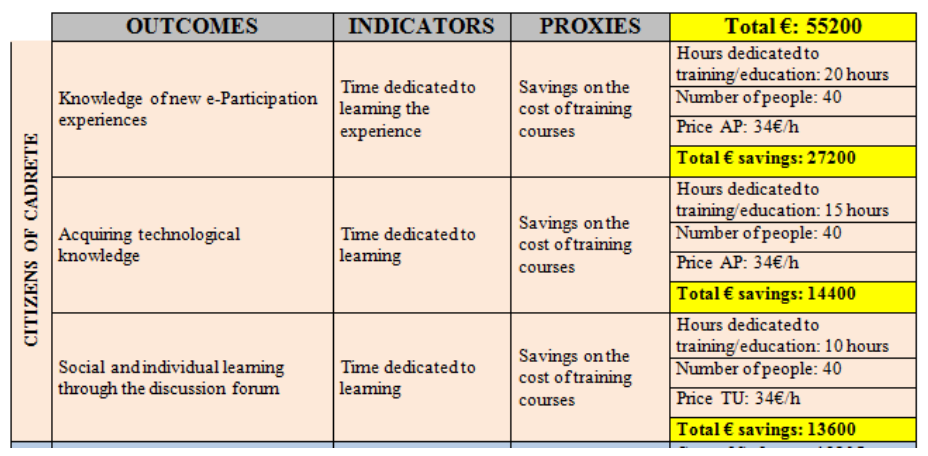

Table 4. Proxies for the indicators of outcomes (GDMZ)

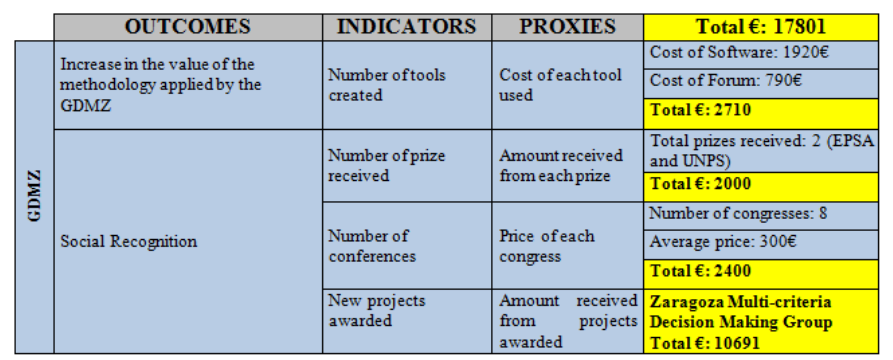

For the outcomes "knowledge of new e-Participation experiences", "acquiring technological knowledge" and "social and individual learning through the discussion forum", the proxy "savings on the cost of training courses" has been used. To quantify them in monetary terms, the following have been taken into account: i) an estimation of the hours that each of the stakeholders would have had to dedicate to training/education, ii) the price per hour that an Associate Professor would charge for giving each of these courses and iii) an estimation of the number of students that would attend these courses. In the case of the council, the 3 people that worked in the council and were responsible for the implementation and the development of the $\mathrm{Ca}$ drete experience were taken into account. In the case of the citizens of Cadrete, the people that participated in the voting process were considered. As there were two rounds in which 43 and 41 people, respectively, participated, in the calculation of the proxy, we have used 40 people as the characteristic sample.

For the outcome "improvement of the council's image through good practice", the proxy "savings on the cost of an advertising campaign" has been used. The Cadrete experience has given the council a good image, leading to a social benefit which, in order to quantify it in monetary terms, has been considered the equivalent of the cost of carrying out an advertising campaign. To estimate this cost, the price of advertising spots and advertisements and the number of adverts have been taken into account. 
To quantify the outcome "foster citizen participation and involvement" the following has been taken into account: i) the time spent by each participant in the voting process (voting) and discussion (sending messages and comments) and ii) the price assigned to each minute spent on both processes $(€ 5 / \mathrm{min})$. It was estimated that a citizen dedicated about 30 minutes to voting (15 minutes per round), 1 minute sending the message and 30 seconds to write a comment associated with a message. The price per minute used ( $€ 5 / \mathrm{min})$ was calculated as follows: a total of three hours (prior training, accreditation, 1st round of voting, discussion forum, 2nd round of voting, survey and closing) was the estimated time needed for each citizen to conduct the experiment. These hours were valued at $€ 60 / \mathrm{h}$. bearing in mind the activities carried out and the amount an external consultant would be willing to charge if they were to participate in the initiative. These $€ 180$ have been distributed over the 36 minutes which on average have been evaluated in the experiment (30 voting and 6 discussion), resulting in $€ 5 /$ minute.

To quantify the outcome "increase in the value of the methodology applied by the GDMZ", the cost of both the software used in the experience and that of the tool of the forum has been taken into account.

Lastly, to quantify the outcome "social recognition" the following have been taken into account: i) the amount received from the two prizes obtained by the GDMZ for the development of the experience ii) the price paid for attending congresses to make known the research projects awarded through the development of the initiative and iii) the number of new projects that have been awarded as a result of the investigation carried out in the implementation of the Cadrete experience.

\subsubsection{Calculation of the SROI coefficient}

This section presents the calculation of the SROI coefficient, that is, the division between the value of the social benefits (value of the outcomes) and the value of the investment (value of the inputs).

Table 5. SROI Coefficient

\begin{tabular}{|l|c|}
\hline \multicolumn{2}{|c|}{$\begin{array}{c}\text { Calculation of the SROI } \\
\text { coefficient }\end{array}$} \\
\hline Social benefits & $115623.50 €$ \\
\hline $\begin{array}{l}\text { Value of the } \\
\text { investment }\end{array}$ & $42046.73 €$ \\
\hline Coefficient & $\mathbf{2 . 7 5}$ \\
\hline
\end{tabular}

The coefficient has a value of 2.75 , which means that, for each monetary unit invested in the Cadrete experience, a return of 2.75 monetary units of social value has been obtained. 


\section{Conclusions and future work}

Carrying out this SROI analysis has allowed the identification and quantification in monetary terms not only of the inputs that were necessary for the implementation and development of the eParticipation experience, based on eCognocracy, that took place in Cadrete but also of the outcomes obtained (social benefits). The relation between the social benefits and the total value of the investments of the experience has allowed us to calculate the SROI coefficient. The value of this coefficient was 2.75 units. This means that, for each monetary unit invested in the Cadrete experience, a return of 2.75 monetary units of social value has been obtained. Furthermore, it leads us to the conclusion that, in the development of an initiative based on eCognocracy, not only economic but also social and environmental value is created.

The carrying out of this SROI analysis shows a social-economic approach to the eParticipation experience, based on eCognocracy, that took place in Cadrete. This approach has allowed to measure the social, environmental and economic impact of an iniciative. As its name indicates, this is an approach and, as such, it has its limitations. Besides, the Cadrete experience is a pilot experience and presents some limitations. This SROI analysis has not taken into account the evaluation of some outcomes, especially the intangible ones. The transparency of the process of participation, stakeholder satisfaction from feeling involved in the experience, cohesion, freedom, and equity are outcomes that have not been evaluated in the carrying out of this analysis due to their intangible nature and to the limitations of the experience. Thus, an immediate future research line will be to establish a methodology that allows the measurement, in monetary terms, of the intangible effects derived from carrying out an eParticipation experience. For this purpose, multi-criteria decision-making techniques will be employed.

Furthermore, in the item of intellectual capital, and in the development and elaboration of the software, the capital received by the GDMZ for the hiring of technical personnel during 2009, 2011 and 2012 has not been taken into account. The total quantity received amounted to 29,183 euros. It is intended that these limitations will be addressed and remedied with the application of the SROI analysis to other eParticipation experiences.

\section{References}

[1] Jaeger, H. (2002). Adaptive nonlinear system identification with echo state networks. Proceedings of NIPS 02, 2002 (8 p.).

[2] Wimmer, M. A. (2002). A European perspective towards online one-stop government: the eGOV project, in Electronic Commerce research and Applications, 1(1) $92-103$.

[3] Moreno-Jiménez, J.M. (2006) "E-cognocracia: Nueva Sociedad, Nueva Democracia”. Estudios de Economía Aplicada 24(1-2), 559-581. 
[4] Moreno-Jiménez, J.M., Polasek, W. (2003): E-democracy and Knowledge. A Multicriteria Framework for the New Democratic Era. Journal Multicriteria Decision Analysis 12, 163-176.

[5] HadziliaS, A.E., (2005). A Methodology Framework for Calculating the Cost of eGovernment Services. M. Böhlen et al. (Eds.): TCGOV 2005, LNAI 3416, 247 - 256. IFIP International Federation for Information Processing 2005.

[6] Matusuda, S., Tsutsui, Y. and Takashima Y. (1998). Evaluation of factors associated with well-being of elderly in an aged society by analytic hierarchy process analysis. Nihon Koshu Eisei Zasshi, 45(8) 704-12.

[7] Bhatnagar, S. (2003). Transparency and Corruption: Does EGovernment Help? DRAFT Paper prepared for the compilation of CHRI 2003 Report Open Sesame: looking for the Right to Information in the Commonwealth, Commonwealth Human Rights Initiative. Available: http://www.iimahd.ernet.in/ subhash/pdfs/CHRIDraftPaper2003.pdf\#search=\% 27can\%20egovernance\%20curb\%20corruption\%20in\%20tax\%20departments

[8] Gupta, M. P. and Jana, D. (2003). "EGovernment evaluation: a framework and case study", in Government Information Quarterly, 20(4), 365-387.

[9] Ajilian, S. and Crameri C. (2011), The economic \& social impact of e - governance.

Available: https://diuf.unifr.ch/main/is/sites/diuf.unifr.ch.main.is/files/documents/studentprojects/eGov_2011_Ajilian_Stefanie_\&_Crameri_Claudio.pdf

[10] Loff, J. (2011). Public Return on Investment: How to determine costs and benefits of EPSA participation and other reform projects. EPSA Trends in Practice Driving Public Sector Excellence to Shape Europe for 2020 (p.105-115). Available: http://issuu.com/eipa-epsa/docs/researchreport_web.

[11] Cuenin, F. (2009). Patrimonio cultural y desarrollo socio económico: la recuperación de áreas centrales históricas. Banco Interamericano de Desarrollo (BDI), Notas Técnicas \# IDB-TN-201 p.28-29.

[12] Azqueta, D. (2007). Introducción a la economía ambiental, McGraw-Hill, 2º edición.

[13] Martínez, E. y Escudey, M. (1998). Evaluación y Decisión Multicriterio - reflexiones y experiencias, Editorial Universidad de Santiago/UNESCO, Santiago de Chile.

[14] O'Sullivan, D. (1991), "Project management in manufacturing using IDEFO," International Journal of Project Management, 9(3), page 162.

[15] Kaplan, Robert S. and Bruns, W. (1987). Accounting and Management: A Field Study Perspective (Harvard Business School Press, 1987) ISBN 0-87584-186-4.

[16] Millar, Ross and Hall, Kelly (2012) Social Return on Investment (SROI) and performance measurement. Public Management Review. pp. 1-19. ISSN 14719037 (In Press)

[17] Moreno-Jiménez, J. M., Pérez-Espés, C. and Velázquez, M. (2014). ECognocracy and the Design of Public Policies. Government Information Quarterly, Vol. 31. 185-194. 